\title{
Filippi syndrome: a new case with skeletal abnormalities
}

Delphine Héron, Thierry Billette de Villemeur, Arnold Munnich, Stanislas Lyonnet

\begin{abstract}
We report on a 9 year old girl, born to consanguineous parents, with major microcephaly, cutaneous syndactyly of the toes, and moderate mental retardation with marked speech involvement. In addition, moderate dysmorphic features and skeletal abnormalities were noted. This multiple congenital anomalies/mental retardation pattern very much resembles that described by Filippi. This observation confirms that this syndrome is a distinct, probably autosomal recessive entity.
\end{abstract}

Pédiatrie,

Hôpital des Enfants-

Malades,

149 rue de Sèvres

75743 Paris Cedex 15,

France

D Héron

T Billette de Villemeur

A Munnich

S Lyonnet

Correspondence to:

Dr Munnich.

Received 24 February 1995

Accepted for publication

29 March 1995
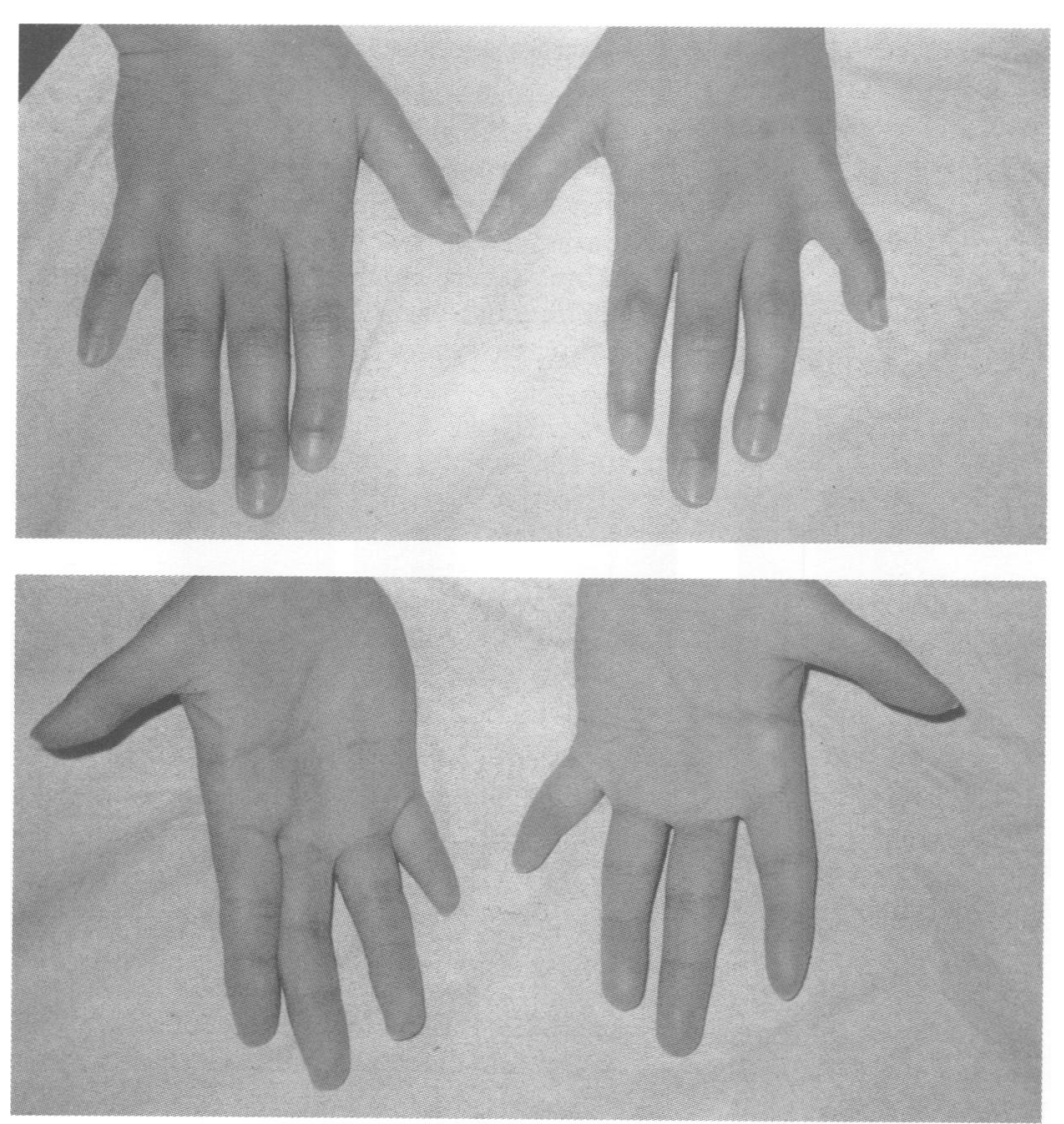

Figure 2 Filippi syndrome: tapered fingers with brachymesophalangism and clinodactyly of the 5th finger.

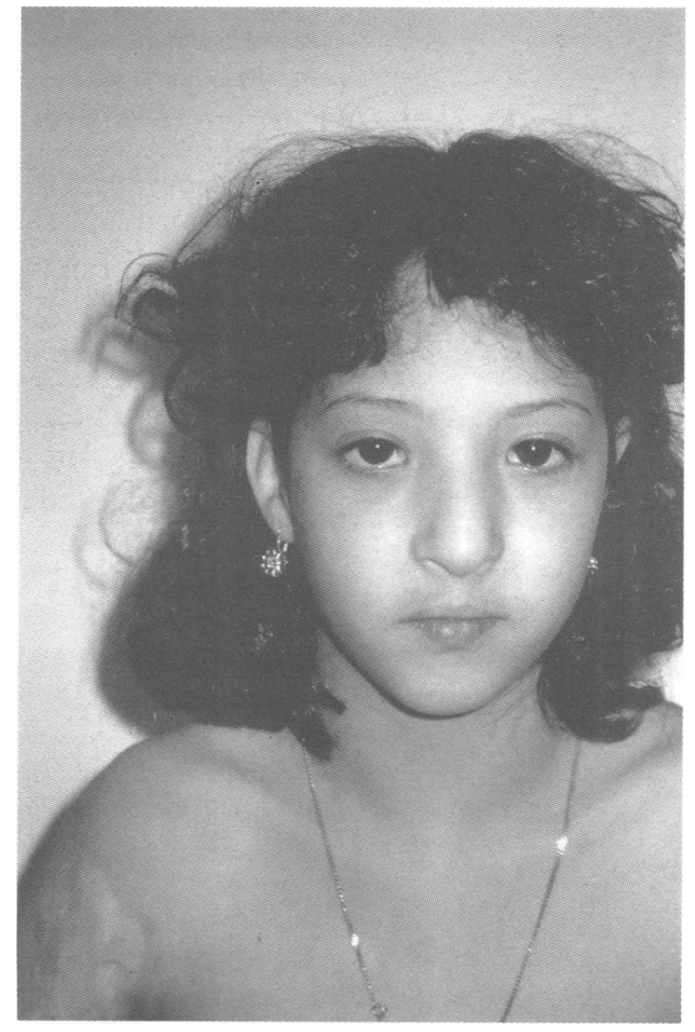

Figure 1 Facial appearance in a case of Filippi syndrome: note the dysmorphic features with high nasal mot.

The proband was the first child of healthy, first cousin parents originating from Tunisia. Her father and mother were 180 and $160 \mathrm{~cm}$ in height respectively. The mother had mild bilateral cutaneous syndactyly between the 2 nd and 3rd toes. Two younger brothers were healthy and the youngest sister had homocystinuria. The pregnancy was uneventful, and spontaneous delivery occurred at 41 weeks, with growth retardation $(46 \mathrm{~cm}$, weight $=$ $2270 \mathrm{~g}$ ) and microcephaly (OFC $30.5 \mathrm{~cm}$, below the 3 rd centile). While motor development was normal, moderate mental retardation and especially speech delay were observed.

At 9 years of age, physical examination showed normal stature $(135 \mathrm{~cm})$ and weight $(26.5 \mathrm{~kg})$, but severe microcephaly (head circumference $45 \mathrm{~cm},-5 \mathrm{SD}$ ). The patient had slightly dysmorphic features including a prominent nasal root (fig 1). The fingers were tapered, with brachymesophalangism and marked clinodactyly of the 5th finger (fig 2). There was bilateral cutaneous syndactyly between the 2nd and 3rd, and 4th and 5th toes (fig 3). There was limitation of pronosupina- 
Clinical features in six patients with Filippi syndrome

\begin{tabular}{|c|c|c|c|c|c|c|c|}
\hline & \multicolumn{3}{|c|}{ Filippi ${ }^{1}$} & \multicolumn{2}{|c|}{ Meinecke ${ }^{2}$} & \multirow{2}{*}{$\begin{array}{l}\text { This } \\
\text { report }\end{array}$} & \multirow[t]{2}{*}{ Total } \\
\hline & 1 & 2 & 3 & 1 & 2 & & \\
\hline Sex & $\mathbf{M}$ & $\mathbf{M}$ & $\mathrm{F}$ & $M$ & $\mathrm{~F}$ & $\mathbf{F}$ & \\
\hline Intrauterine growth retardation & + & + & + & + & + & + & $6 / 6$ \\
\hline Mental retardation & + & + & + & + & + & + & $6 / 6$ \\
\hline Dysmorphism & + & + & + & + & + & + & $6 / 6$ \\
\hline Microcephaly & + & + & + & + & + & + & $6 / 6$ \\
\hline Short stature & + & + & + & + & + & - & $5 / 6$ \\
\hline \multicolumn{8}{|l|}{ Syndactyly } \\
\hline Feet & + & + & + & + & + & + & $6 / 6$ \\
\hline Hands & + & + & - & + & + & - & $4 / 6$ \\
\hline Elbow dislocation & - & - & - & - & - & + & $1 / 6$ \\
\hline Brachymesophalangism of the 5 th finger & + & + & ? & + & + & + & $5 / 6$ \\
\hline Delayed bone age & + & - & $?$ & $?$ & - & - & $1 / 4$ \\
\hline
\end{tabular}

tion, and ankylosis of the interphalangeal joints of both thumbs with an absent flexion crease.

Skeletal $x$ rays showed brachymesophalangism of the 5th finger, hypoplasia of the radial heads with complete dislocation of the elbows, and bilateral synostosis of the carpal bones (figs 4 and 5). Laboratory data were normal, including plasma and urine amino acid chromatograms. Cerebral CT scan, electroencephalogram, and blood karyotype ( $G$ banding) were normal.

The main features in our patient were intrauterine growth retardation, major micro-
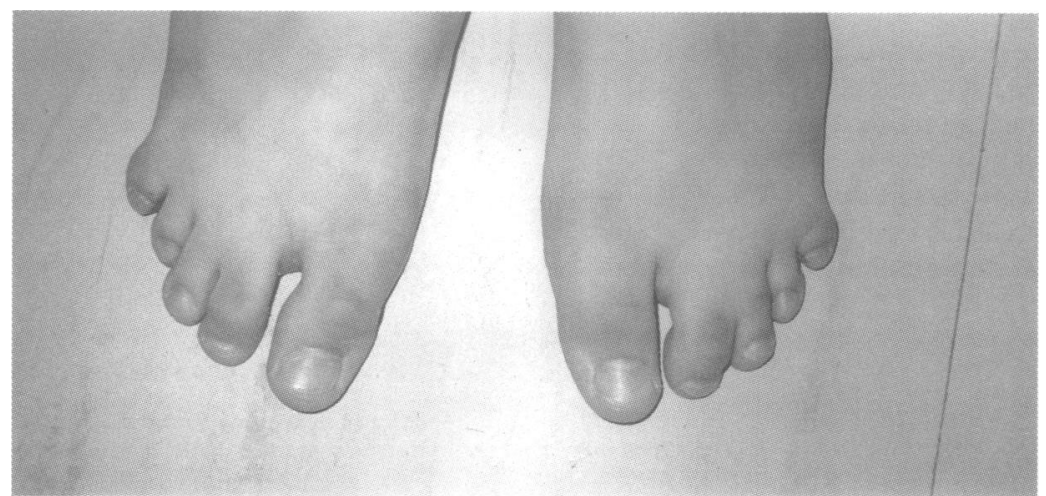

Figure 3 Cutaneous syndactyly of toes.
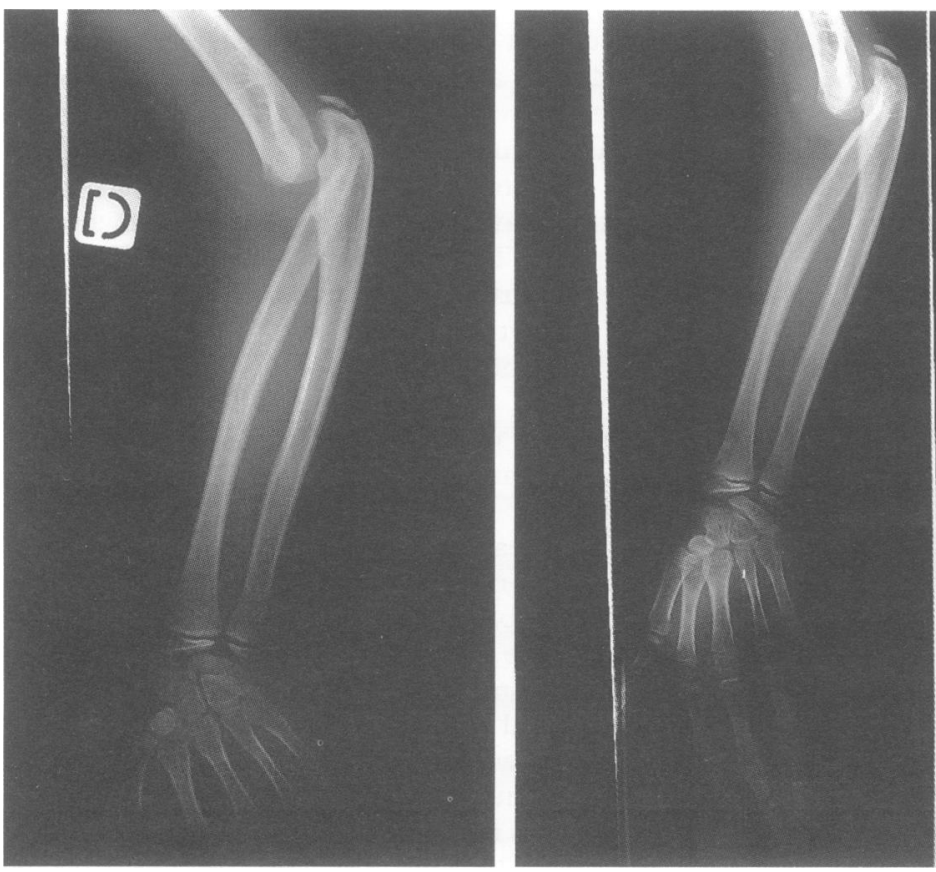

Figure 4 Hypoplasia of radial heads and dislocation of the elbows. cephaly $(<-5 \mathrm{SD})$, cutaneous syndactyly of the toes, and moderate mental retardation with marked speech involvement. In addition, moderate dysmorphic features were noted, including a prominent nasal root that was not a familial feature. This multiple congenital anomalies/mental retardation syndrome (MCA/ $M R$ ) very much resembles that described by Filippi ${ }^{1}$ and recently reported in other families by Meinecke. ${ }^{2}$ All patients have in common severe microcephaly (always <-3 SD) of prenatal origin, syndactyly of the feet/hands, typical distinct facial dysmorphism with a particularly prominent nasal root, and variable degrees of mental retardation with speech delay. Bone age was retarded in one out of the four patients in whom this was determined and brachymesophalangism of the 5th finger was observed in all but one. However, postnatal short stature was not seen in our patient. On the other hand, more pronounced skeletal anomalies were present, such as dislocation of the elbows with hypoplasia of the radial heads, and carpal synostosis. Further radiological investigations would be of interest in the patients reported by Filippi ${ }^{1}$ and Meinecke. ${ }^{2}$ The karyotype was normal in all of six patients (table).

This recently described MCA/MR syndrome is characterised by intrauterine growth retardation, severe microcephaly, syndactyly of the feet/hands, variable skeletal involvement, moderate to severe mental retardation with
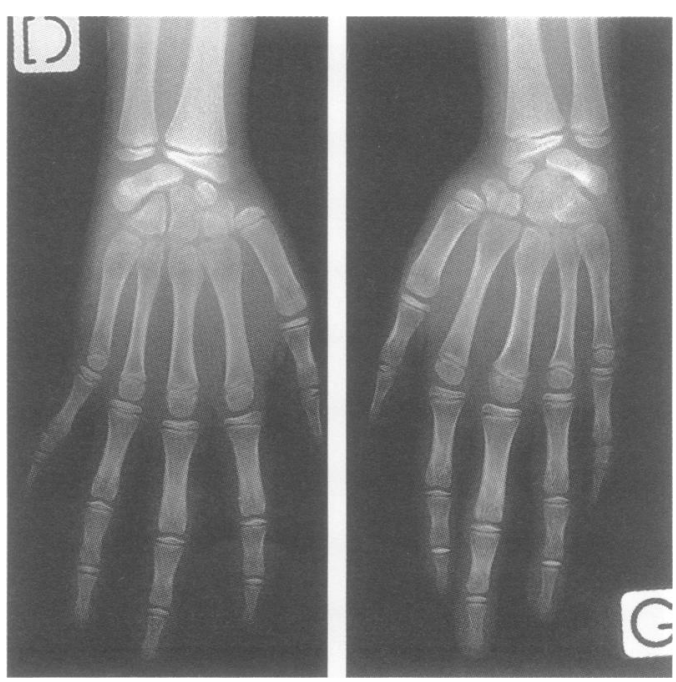

Figure 5 Synostosis of two carpal bones and brachymesophalangism of the 5th finger. 
speech delay, and dysmorphic features that are part of the syndrome. Occurrence of the disease in both sexes ${ }^{12}$ and consanguinity in our report add to the view that an autosomal recessive mode of inheritance is likely in Filippi syndrome.

Lorenz et $a l^{3}{ }^{3}$ Scott $e t a l,{ }^{4}$ and Zerres $e t a l^{5}$ independently reported two distinct MCA/MR syndromes with microcephaly, syndactyly, and short stature. However, in both cases, the facial appearance is very different from the dysmorphism observed in Filippi syndrome. Moreover, microcephaly in the patient reported by Zerras $e t a l^{5}$ is of postnatal occurrence and only boys have been affected with Scott syndrome, suggesting an $\mathrm{X}$ linked mode of inheritance. Thus, Filippi syndrome appears to be an independent and possibly homogeneous genetic condition.
Since the submission of this paper, another case of Filippi syndrome has been reported by Toriello et al. ${ }^{6}$

We thank G Filippi and M Le Merrer for helpful comments and Alan Strickland for his help in preparing this manuscript.

1 Filippi G. Unusual facial appearance, microcephaly, growth and mental retardation, and syndactyly. A new syndrome? Am 7 Med Genet 1985;22:821-4.

2 Meinecke P. Short stature, microcephaly, characteristic face, syndactyly and mental retardation: the Filippi syndrome. syndactyly and mental retardation: the Filippi syndrome.

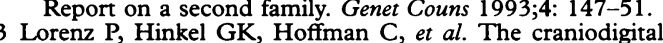
syndrome of Scott: report of a second family. Am $\mathcal{J}$ Med
serenz syndrome of Scott: repor

4 Scott CR, Bryant JI, Graham CB. A new craniodigital syndrome with mental retardation. $\mathcal{F}$ Pediatr $1971 ; 78: 658-63$

5 Zerres K, Rietschel M, Rietschel E, Majewski F, Meinecke P. Postnatal short stature, microcephaly, severe syndactyly of hands and feet, dysmorphic face, and mental retardation: a new syndrome? f Med Genet 1992;29:269-71.

6 Toriello HV, Higgins JV. Craniodigital syndromes: report of a child with Filippi syndrome and discussion of differential diagnosis. Am f Med Genet 1995;55:200-4. 